\title{
EVALUASI PROSES IMPLEMENTASI POSBINDU PTM DI WILAYAH KERJA PUSKESMAS SIMPANG SUNGAI DUREN KECAMATAN JAMBI LUAR KOTA KABUPATEN MUARO JAMBI TAHUN 2017
}

\section{Evaluation of the Implementation Process of Posbindu PTM in Working Area of Simpang Sungai Duren Public Health Center of Jambi Sub-District of Muaro Jambi Regency in 2017}

\author{
Ramadhani Eka Putri ${ }^{1}$, Hubaybah $^{2}$, Asparian ${ }^{2}$ \\ ${ }^{1}$ Program Studi Kesehatan Masyarakat, Fakultas Kesehatan Masyarakat, Universitas Jambi \\ ${ }^{2}$ Dosen Ilmu Kesehatan Masyarakat, Fakultas Kesehatan Masyarakat, Universitas Jambi
}

\begin{abstract}
Abstrak
Data Dinas Kesehatan Kabupaten Muaro Jambi tahun 2017 terlihat bahwa Puskesmas Simpang Sungai Duren merupakan Puskesmas terbanyak yang berhasil membentuk Posbindu PTM di Kecamatan Jambi Luar Kota. Persentase terbentuknya Posbindu PTM 77,8\% berarti tujuh Posbindu PTM terbentuk di tujuh desa dari sembilan desa wilayah kerja serta ada lima Posbindu PTM yang aktif mengimplementasikan Posbindu PTM selama minimal satu tahun terakhir. Tujuan penelitian ini yaitu mengetahui proses implementasi Posbindu PTM di Wilayah Kerja Puskesmas Simpang Sungai Duren Kecamatan Jambi Luar Kota Kabupaten Muaro Jambi. Penelitian ini menggunakan metode penelitian kualitatif dengan rancangan studi kasus. Pengumpulan data melalui metode wawancara mendalam dan dokumentasi. Pemeriksaan keabsahan data memanfaatkan teknik triangulasi sumber, metode dan teori. Hasil evaluasi proses implementasi yaitu Posbindu PTM di Wilayah Puskesmas Simpang Sungai Duren telah melaksanakan pelayanan sistem lima meja. Pada masing-masing kategori implementasi terdapat beberapa kendala yaitu belum memiliki tempat khusus pelaksanaan Posbindu PTM, peran kader belum optimal, kurangnya jumlah kader, minimnya sumber dana, kurangnya koordinasi hasil kegiatan dengan pemangku kepentingan dan kader belum mampu memberikan edukasi KMS-FR serta pelaporan dengan sistem online. Ada perbedaan antara proses implementasi Posbindu PTM yang telah dilaksanakan dengan Standar Operasional Prosedur (SOP) pada pedoman implementasi Posbindu PTM.
\end{abstract}

Kata Kunci : Proses, Implementasi, Posbindu, SOP

\begin{abstract}
Data of Muaro Jambi District Health Office in 2017 shows that Simpang Sungai Duren Public Health Center is the most Puskesmas that managed to establish Posbindu PTM in Kecamatan Jambi Luar Kota. The percentage of Establishment of Posbindu PTM 77.8\% means seven Posbindu PTM formed in seven villages from nine working area villages and there are five Posbindu PTM actively implementing Posbindu PTM for at least the last one year. The purpose of this research is to know the implementation process of Posbindu PTM in Working Area of Simpang Sungai Duren Public Health Center of Jambi Sub-District of Muaro Jambi Regency. This research uses qualitative research method with case study design. Data collection through in-depth interview method and documentation. Data validity checks utilize source triangulation techniques, methods and theory. The result of the evaluation of the implementation process of Posbindu PTM in Simpang Sungai Duren Public Health Center has implemented five table service system. In each category of implementation there are some obstacles that are not yet have a special place of implementation of Posbindu PTM, the role of cadre not optimal, lack of cadre number, lack of fund source, lack of coordination result of activity with stakeholders and cadre not yet able to provide KMS-FR education and reporting with online system. There is a difference between the implementation process of Posbindu PTM which has been implemented with Standard Operational Procedure (SOP) on the guidance of PTM Posbindu implementation.
\end{abstract}

Keywords: Process, Implementation, Posbindu, SOP

Korespondensi : Ramadhani Eka Putri

Email : rep16putry@gmail.com 


\section{PENDAHULUAN}

Penyakit Tidak Menular (PTM) merupakan penyakit yang kejadian penularannya tidak melalui rantai penularan tertentu, memiliki masa inkubasi yang lama dan laten ${ }^{1}$. Penyakit tersebut lebih banyak disebabkan oleh gaya hidup manusia. Kematian akibat PTM diperkirakan akan terus meningkat diseluruh dunia, peningkatan terbesar terjadi di negara-negara menengah dan miskin. PTM menjadi penyebab kematian 36 juta atau hampir dua pertiga dari 57 juta kematian di dunia ${ }^{2}$.

Di Indonesia beberapa PTM cenderung mengalami peningkatan, prevalensi diabetes melitus dari 2,1 \% tahun 2013 meningkat menjadi 6,7 \% tahun 2014 dan prevalensi Penyakit Jantung Koroner (PJK) dari 1,5\% tahun 2013 menjadi 12,9\% tahun 2014 ${ }^{3,4}$. Di Provinsi Jambi prevalensi gastritis dari 10,30\% tahun 2013 meningkat mejadi 11,37\% tahun 2014 sedangkan prevalensi hipertensi mengalami penurunan dari 12,63\% tahun 2013 menjadi $12,16 \%$ tahun $2014^{5,6}$. Penyakit Tidak Menular (PTM) di Puskesmas Simpang Sungai Duren diantaranya, yaitu 114 kasus Hipertensi tahun 2016 meningkat menjadi 244 kasus tahun 2017, 40 kasus diabetes mellitus tahun 2016 meningkat menjadi 51 kasus tahun 2017, dan 13 kasus Penyakit Jantung Koroner (PJK) tahun 2016 meningkat menjadi 26 kasus tahun 2017.

Upaya pengendalian PTM dibangun berdasarkan komitmen bersama dari seluruh elemen masyarakat yang peduli terhadap ancaman PTM melalui posbindu PTM. Pengembangan posbindu PTM merupakan bagian integral dari sistem pelayanan kesehatan, diselenggarakan berdasarkan permasalahan PTM yang ada dimasyarakat, mencakup berbagai upaya promotif dan preventif serta pola rujukan. Pos Pembinaan Terpadu Penyakit Tidak Menular (Posbindu PTM) merupakan peran serta masyarakat dalam kegiatan deteksi dini dan pemantauan resiko PTM Utama yang dilaksanakan secara terpadu, rutin, dan periodik. Tujuan pelaksanaan Posbindu PTM untuk meningkatkan peran serta masyarakat dalam mencegah dan menemukan secara dini faktor risiko PTM. Sasarannya yaitu kelompok masyarakat sehat, berisiko dan penyandang PTM berusia 15 tahun ke atas. Posbindu PTM diselenggarakan dalam sebulan sekali ${ }^{7}$.

Proses implementasi Posbindu PTM menurut Standar Operasional Prosedur (SOP) yakni Posbindu PTM diselenggarakan dalam sebulan sekali bila diperlukan dapat lebih, lokasinya diwilayah yang mudah dijangkau dan nyaman, menggunakan sistem 5 meja, terdapat pembiayaan yang memadai, pencatatan dan pelaporan, tindak lanjut hasil kegiatan, rujukan Posbindu PTM serta pelaksanaan kegiatan sesuai dengan tipe Posbindu PTM yang dibentuk di desa tersebut. Tipe Posbindu PTM terbagi dua yakni Posbindu PTM dasar dan Posbindu PTM utama? .

Di Indonesia tahun 2016 terdapat 4.773 Puskesmas yang membina Posbindu PTM, 12.349 desa yang melaksanakan Posbindu PTM dari 21.470 total Posbindu PTM. Namun Posbindu PTM di Indonesia memiliki permasalahan berdasarkan Permenkes RI Nomor 5 Tahun 2017 diantaranya, yaitu hanya 3.723 Posbindu PTM dari 7.225 Posbindu PTM yang telah aktif melakukan input data secara elektronik. Tantangan penanggulangan PTM secara umum, yaitu Sumber Daya Manusia (SDM), infrastruktur, struktur organisasi dan finansial masih relative terbatas di daerah. Sedangkan Provinsi Jawa Timur merupakan provinsi dengan angka tertinggi pada jumlah desa yang melaksanakan Posbindu PTM yakni 2.472 Posbindu PTM dan angka terendah di Provinsi Kalimantan Utara yakni 33 Posbindu PTM serta Provinsi 
Jambi berada pada urutan 12 terbanyak yakni 360 Posbindu $^{8}$.

Provinsi Jambi tediri dari 1508 desa dengan 360 desa berposbindu tahun 2016 yang meningkat menjadi 663 desa berposbindu tahun 2017 dan 612 total Posbindu PTM tahun 2016 meningkat menjadi 728 total Posbindu PTM tahun $2017^{8}$. Kabupaten Muaro Jambi terdiri dari 155 desa dengan 51 desa berposbindu dan 51 desa total Posbindu PTM yang tersebar di 11 kecamatan pada berberapa wilayah Puskesma. Di Puskesmas Simpang Sungai Duren Kecamatan Jambi Luar Kota membentuk dan mengimplementasikan Posbindu PTM dengan persentase $77,8 \%$ berarti 7 Posbindu PTM yang tersebar di tujuh desa dari sembilan desa diwilayah kerja puskes tersebut.

Berdasarkan hasil studi dokumentasi pada data Posbindu PTM di Dinas Kesehatan Kabupaten Muaro Jambi tahun 2017 terlihat Puskesmas Simpang Sungai Duren merupakan wilayah kerja terbanyak yang berhasil membentuk dan mengimplementasikan Posbindu PTM di Kecamatan Jambi Luar Kota. Berdasarkan data dibidang pengelola program Posbindu Puskesmas Simpang Sungai Duren terdapat tujuh Posbindu PTM. Pada tahun 2016 terdapat 5 desa yang telah membentuk Posbindu PTM, yaitu Desa Pematang Gajah, Desa Mendalo Indah, Desa Simpang Sungai Duren, Desa Mendalo Darat, dan Kelurahan Pijoan serta pada tahun 2017 terbentuk Posbindu PTM di Desa Danau Sarang Elang dan Sungai Duren.

Pelaksanaan Posbindu PTM di Wilayah Kerja Puskemas Simpang Sungai Duren pada tahun 2016 terdapat 5 Posbindu PTM yang dikategorikan pelaksanaannya aktif selama satu tahun terakhir dan 2 Posbindu PTM belum aktif satu tahun terakhir karena baru terbentuk pada tahun 2017. Tipe Posbindu PTM diwilayah tersebut yakni tipe Posbindu PTM dasar sedangkan kendala dalam pelaksanaan Posbindu PTM diwilayah Puskesmas Simpang Sungai Duren diantaranya sarana dan prasarana yang kurang memadai, kurangnya kader, dan kehadiran peserta Posbindu PTM tidak rutin berdasarkan studi pendahuluan di Bidang Pengelola Program Posbindu PTM di Puskesmas Simpang Sungai Duren tahun 2017. Dalam penelitian Prinduri (2015) menjelaskan bahwa dalam pelaksanaan Posbindu PTM jumlah petugas belum efektif untuk menjalankan program tersebut dan peralatan yang tersedia terbatas ${ }^{9}$. Sedangkan penelitian Indah (2015) menyatakan bahwa input Sumber Daya Manusia (SDM) ketersediaan tenaga pelaksana belum sesuai dengan pedoman yang ada $^{10}$. Hasil penelitian Astuti, Prasetyo dan Ariyanto (2016) menyatakan bahwa pencatatan dan pelaporan pada Posbindu PTM masih menggunakan sistem manual bukan online $^{11}$. Berdasarkan permasalahan pada latar belakang diatas, maka peneliti merasa layak untuk melakukan penelitian evaluasi proses implementasi Posbindu PTM di wilayah kerja Puskesmas Simpang Sungai Duren Kecamatan Jambi Luar Kota Kabupaten Muaro Jambi.

\section{METODE}

Penelitian ini merupakan jenis penelitian kualitatif yang mengungkapkan situasi sosial tertentu dengan mendeskripsikan kenyataan secara benar, dibentuk oleh kata - kata berdasarkan teknik pengumpulan dan analisis data yang relevan yang diperoleh dari situasi alamiah $^{12}$. Rancangan yang digunakan yaitu studi kasus dimana peneliti mengkaji program, kejadian, aktivitas, dan proses secara mendalam $^{13}$. Penelitian ini merupakan evaluasi proses implementasi untuk mengetahui pada tingkatan mana program Posbindu PTM secara efektif diterapkan ${ }^{14}$. Pengumpulan data melalui metode wawancara mendalam dan dokumentasi. Pemeriksaan 
keabsahan data memanfaatkan teknik triangulasi sumber, metode dan teori ${ }^{15,16}$. Informan dalam penelitian ini diambil dengan menggunakan teknik purposive, yaitu teknik yang dilakukan untuk memilih informan, menentukan subjek atau objek sesuai tujuan penelitian dengan menggunakan pertimbangan pribadi yang sesuai dengan topik penelitian ${ }^{12}$. Informan penelitian terdiri dari 15 orang, yakni 1 orang pengelola program Posbindu PTM di Pusekesmas, 5 orang kader aktif Posbindu PTM, 4 orang kepala desa, dan 5 orang bidan desa.

\section{HASIL DAN PEMBAHASAN}

Evaluasi proses implementasi Posbindu PTM merupakan suatu metode yang digunakan untuk mengetahui gambaran apakah proses tahapan implementasi Posbindu PTM telah sesuai dengan Standar Operasional Prosedur (SOP) dan bagaimana gambaran proses pelaksanaan Posbindu PTM telah berkembang. Pada proses implementasi Posbindu PTM terdapat beberapa indikator pendukung yakni waktu pelaksanaan Posbindu PTM, tempat pelaksanaan Posbindu PTM, pelaksanaan kegiatan Posbindu PTM, peran kader Posbindu PTM, peran petugas puskesmas dalam pelaksanaan Posbindu PTM, peran pemangku kepentingan dalam pelaksanaan Posbindu PTM, pembiayaan untuk Posbindu PTM, pencatatan dan pelaporan kegiatan Posbindu $\mathrm{PTM}^{7}$.

Berdasarkan hasil penelitian mengenai evaluasi proses implementasi Posbindu PTM di Wilayah Kerja Puskesmas Simpang Sungai Duren Kecamatan Jambi Luar Kota Kabupaten Muaro Jambi, lima desa yang telah aktif mengimplementasikan Posbindu PTM minimal satu tahun pada Wilayah Kerja Puskesmas Simpang Sungai Duren yaitu Desa Pematang Gajah, Mendalo Indah, Mendalo Darat, Simpang Sungai Duren, dan Kelurahan
Pijoan. Posbindu PTM pada lima desa tersebut terbentuk pada tahun 2016 dengan tingkatan Posbindu PTM Dasar.

Adapun hasil penelitian dan pembahasan tentang Evaluasi Proses Implementasi Pos Pembinaan Terpadu Penyakit Tidak Menular (Posbindu PTM) di Wilayah Kerja Puskesmas Simpang Sungai Duren Kecamatan Jambi Luar Kota Kabupaten Muaro Jambi, diuraikan dalam beberapa kategori berdasarkan konsep evaluasi proses implementasi Posbindu, sebagai berikut :

1. Waktu Pelaksanaan Posbindu PTM

Jadwal penyelenggaraan Posbindu PTM di Wilayah Kerja Puskesmas Simpang Sungai Duren dilaksanakan minimal satu kali dalam sebulan. Pada beberapa desa yang berposbindu di Wilayah Kerja Puskesmas Simpang Sungai Duren di dalam satu desa terdapat beberapa tempat pelaksanaan Posbindu PTM sehingga waktu pelaksanaan setiap tempat tersebut satu kali dalam tiga bulan. Hal tersebut dikarenakan wilayah desa yang terlalu luas. Kader dan bidan desa berinisiatif untuk melaksanakan kegiatan Posbindu PTM tidak hanya satu kali dalam sebulan agar mampu mencover masyarakat di wilayah tersebut.

Berdasarkan hasil penelitian waktu pelaksanaan Posbindu PTM telah memenuhi Standar Operasional Prosedur (SOP), karena setiap desa yang memiliki Posbindu PTM menyelenggarakan Posbindu PTM minimal satu kali dalam sebulan. Kehadiran peserta masih sedikit meskipun pelaksanaannya tidak hanya satu kali dalam sebulan dengan alasan masyarakat banyak yang bekerja pada hari dan waktu tersebut.

Menurut teori Darmawan dan Sjaaf (2016) menyatakan bahwa waktu merupakan salah satu yang menjadi indikator untuk mengevaluasi suatu program, apakah waktu tersebut telah sesuai dengan kebutuhan dalam melaksanakan program. Jika waktu yang dipilih dalam melaksanakan suatu program 
tidak efektif dan efisien maka program tersebut tidak dapat terlaksana secara optimal $^{17}$

Penentuan jadwal pelaksanaan Posbindu PTM di Wilayah Kerja Puskesmas Simpang Sungai Duren ditentukan berdasarkan kesepakatan kader dan bidan desa hanya beberapa desa yang mengikutsertakan peran pihak lain baik pemangku kepentingan maupun petugas puskesmas dalam penentuan jadwal. Hal tersebut memberikan dampak terhadap keberhasilan pelaksanaan kegiatan seperti, pertama petugas Puskesmas tidak rutin menghadiri pelaksanaan Posbindu PTM sehingga peran puskesmas tidak berjalan optimal dalam proses implementasi Posbindu PTM, kedua rendahnya kuantitas kehadiran masyarakat karena waktu pelaksanaannya bersamaan dengan jam kerja terutama bagi laki-laki. Sejalan dengan penelitian Soleha (2017) menyatakan bahwa indikator heteroglasia faktor keberagaman kader dan masyarakat diakomodasikan dan dimanfaatkan untuk saling berbagi informasi, pengetahuan dan pengalaman mengenai Posbindu PTM diantara mereka ${ }^{18}$. Peran berbagai pihak dibutuhkan dalam memberikan informasi untuk penentuan jadwal yang efektif dan efisien pada implementasi Posbindu PTM sehingga diharapkan mampu mengurangi permasalahan kuantitas kehadiran peserta dan petugas Posbindu PTM.

Disini terlihat adanya keterkaitan antara kategori penentuan waktu dengan kategori peran serta semua pihak yang terkait dengan Posbindu PTM. Pemangku kepentingan khususnya kepala desa atau lurah juga berperan penting dalam penentuan jadwal baik hari maupun waktunya, karena kepala desa atau lurah lebih mengetahui karakteristik masyarakat yang berada dalam tanggungjawabnya baik dari waktu kerja masyarakat pada umumnya maupun waktu kegiatan masyarakat di desa tersebut sehingga perlu adanya koordinasi yang baik dalam penentuan jadwal dengan kepala desa atau lurah. Peran kader dalam menyusun dan menentukan jadwal yakni berkoordinasi dengan kepala desa atau lurah untuk mendapatkankan informasi yang tepat dan akurat agar pelaksanaan Posbindu PTM tepat pada waktu masyarakat tidak sibuk bekerja ataupun kegiatan desa lainnya begitu juga dengan petugas Puskesmas dikoordinasikan kembali agar petugas Puskesmas siap membantu pada jadwal tersebut serta mengurangi risiko jadwal yang bersamaan dengan kegiatan lain petugas. Ketepatan penentuan jadwal pelaksanaan Posbindu PTM berdampak pada kehadiran peserta Posbindu PTM.

Musyawarah Masyarakat Desa (MMD) merupakan pertemuan perwakilan warga desa untuk membahas prioritas masalah kesehatan yang akan diatasi, menggali potensi sumber daya yang dimiliki dan penyusunan rencana intervensi ${ }^{19}$.Pada penyusunan dan penentuan jadwal Posbindu PTM di Wilayah Kerja Puskesmas Simpang Sungai Duren Kecamatan Jambi Luar Kota Kabupaten Muaro Jambi dibutuhkan peran serta semua pihak untuk menyepakati hal tersebut melalui kegiatan Musyawarah Masyarakat Desa (MMD) bersama kader, petugas puskesmas, maupun pemangku kepentingan yang ada di desa berposbindu tersebut agar jadwal tersebut dapat dilaksanakan sesuai rencana dan kebutuhan.

\section{Tempat Pelaksanaan Posbindu PTM}

Tempat pelaksanaan Posbindu PTM di Wilayah Kerja Puskesmas Simpang Sungai Duren tidak dalam satu tempat yang tetap dan khusus pada setiap desa. Pelaksanaan kegiatan tersebut dilaksanakan diberbagai tempat diantaranya bergabung dengan tempat pelaksanaan Posyandu, dirumah warga sebelum pelaksanaan yasinan, di balai desa, di 
Puskesmas Pembantu (Pustu), maupun pada kegiatan PKK di desa tersebut. Jika pelaksanaan Posbindu PTM hanya pada satu tempat maka tidak semua masyarakat didesa tersebut bisa mengikuti Pobindu PTM dan bangunan khusus untuk Posbindu PTM belum tersedia disetiap desa.

Pada beberapa desa, kader mengalami kesulitan dalam proses pengimplementasian Posbindu PTM karena bangunan tempat pelaksanaan Posbindu PTM kurang luas disebabkan oleh pelaksanaannya bergabung dengan beberapa kegiatan desa lainnya sehingga ruang kegiatan tersebut kurang kondusif dan kurang nyaman, sedangkan pada SOP masyarakat seharusnya mendapatkan tempat yang nyaman untuk pelaksanaan Posbindu PTM.

Berdasarkan pedoman penyelenggaraan posbindu PTM yaitu tempat pelaksanaan Posbindu PTM sebaiknya berada pada lokasi yang mudah dijangkau dan nyaman bagi peserta serta dapat dilaksanakan diberbagai tempat $^{7}$. Berdasarkan hasil penelitian tempat pelaksanaan Posbindu PTM belum memenuhi Standar Operasional Prosedur (SOP), karena ada beberapa bangunan tempat pelaksanaan Posbindu PTM membuat masyarakat tidak nyaman untuk mengikuti kegiatan Posbindu PTM ketika pelaksanaannya digabung dengan kegiatan lain masyarakat.

Pada penelitian ini ditemukan beberapa kendala pengadaan tempat khusus pelaksanaan Posbindu PTM di Wilayah Kerja Puskesmas Simpang Sungai Duren yang meliputi: 1) belum adanya tanah yang tersedia khusus ataupun donatur yang bersedia menyumbangkan tanah untuk membangun tempat pelaksanaan Posbindu PTM; 2) belum adanya bangunan khusus yang bisa dijadikan tempat Pelaksanaan Posbindu PTM sehingga pelaksanaan Posbindu PTM tersebut dilaksanakan bersamaan di tempat Posyandu, diacara yasinan, di balai desa, di Puskesmas
Pembantu, dan ketika acara PKK desa; 3) belum adanya partisipasi dari berbagai pihak maupun masyarakat untuk bersama-sama menemukan solusi permasalahan pengadaan tempat. Sejalan dengan teori Mardikanto dan Soebiato (2012;81-84) menyatakan bahwa partisipasi masyarakat dalam pengambilan keputusan pembangunan perlu ditumbuhkan melalui dibukanya forum yang memungkinkan masyarakat banyak berpartisipasi langsung dalam proses pengambilan keputusan tentang program-program pembangunan di wilayah setempat $^{20}$.

Sumber daya modal yang didalamnya termasuk bangunan, tanah, dan sarana kesehatan merupakan penentu keberhasilan pelaksanaan suatu program ${ }^{21}$. Sedangkan berdasarkan hasil penelitian sumber daya modal khususnya bangunan dan tanah belum memenuhi SOP, hal ini dapat mempengaruhi terhadap keberhasilan pelaksanaan Posbindu PTM sehingga diperlukan tindakan ataupun pergerakan agar sumber daya modal terpenuhi dan tidak menimbulkan permasalahan ataupun kendala untuk kedepannya dalam pelaksanaan Posbindu PTM.

Kesadaran masyarakat untuk berpartisipasi baru akan tumbuh jika masyarakat telah mengetahui tentang adanya masalah yang sedang dihadapi dan memerlukan upaya pemecahannya ${ }^{20}$. Hal ini menunjukkan bahwa dalam pengadaan tempat Posbindu PTM di Wilayah Kerja Puskesmas Simpang Sungai Duren diperlukan adanya kegiatan komunikasi pembangunan yang mampu memberikan pesan agar mampu membangkitkan, menumbuhkan, memotivasi dan menggerakkan masyarakat untuk mampu secara mandiri dalam pengadaan pembangunan gedung khusus pelaksanaan Posbindu PTM di wilayah setempat. Kegiatan komunikasi tersebut dapat direalisasikan pada kegiatan Musyawarah Masyarakat Desa (MMD). 
Meskipun petugas telah melaksanakan Posbindu PTM diberbagai tempat namun keadiran masyarakat masih kurang, karena kurangnya kesadaran msyarakat akan pentingnya mengikuti Posbindu PTM dan masih adanya persepsi masyarakat lebih baik langsung pemriksaan kesehatan kepada dokter keluarga. Ditinjau dari hasil penelitian yang dibandingkan dengan beberapa teori maupun penelitian sejenis terlihat perlu adanya evaluasi, salah satunya evaluasi pengaruh (impact evaluation) yang menilai perubahan yang terjadi sebagai akibat intervensi yang dilakukan program ${ }^{22}$. Terdapat keterkaitan yang berpengaruh terhadap keberhasilan program Posbindu PTM di Wilayah Puskesmas Simpang Sungai Duren yakni keterkaitan antara indikator tempat pelaksanaan posbindu, peran kader, peran petugas puskesmas, peran pemangku kepentingan serta partisipasi dari masyarakat untuk sama-sama mengambil andil dalam menemukan solusi permasalahan pengadaan tempat Posbindu PTM yang dapat direalisasikan melalui musyawarah masyarakat desa.

\section{Pelaksanaan Kegiatan Posbindu PTM \\ Pelaksanaan kegiatan Posbindu PTM di} Wilayah Kerja Puskesmas Simpang Sungai Duren dilaksanakan menggunakan pelayanan sistem lima meja dengan tipe Posbindu PTM dasar pada setiap desa. Berdasarkan Kementrian Kesehatan Republik Indonesia tahun 2013 tentang pedoman penyelenggaraan posbindu PTM yaitu Posbindu PTM diselenggarakan menggunakan lima tahapan layanan atau sistem lima meja, namun dalam situasi kondisi tertentu bisa disesuaikan kembali dengan kebutuhan dan kesepakatan. Berdasarkan hasil penelitian pelaksanaan kegiatan Posbindu PTM di Wilayah Kerja Puskesmas Simpang Sungai Duren telah sesuai SOP karena telah menggunakan pelayanan lima meja, namun masih terdapat hambatan ketika pelaksanaan kegiatan tersebut.

Pelayanan sistem lima meja tersebut tidak hanya digerakkan oleh kader, namun juga dibantu oleh tenaga kesehatan lainnya seperti bidan desa, dokter, perawat, dan ahli gizi. Penyelenggaraan kegiatan Posbindu PTM lebih dominan digerakkan oleh bidan desa, karena kader belum terlalu memahami mengenai Posbindu PTM. Pelayanan lima meja pada beberapa desa berposbindu masih belum beraturan, namun tetap memenuhi sistem pelayanan lima meja serta diselingi dengan senam bersama pada beberapa desa yang berposbindu. Hal ini dikarenakan kuantitas jumlah kader yang belum sesuai SOP.

Tabel 1. Desa yang Memiliki Posbindu Kit Di Wilayah Kerja Puskesmas Simpang Sungai Duren Tahun 2017

\begin{tabular}{lcc}
\hline \multirow{2}{*}{$\begin{array}{c}\text { Desa/Kelurahan } \\
\text { Berposbindu } \\
\text { PTM }\end{array}$} & \multicolumn{2}{c}{$\begin{array}{c}\text { Jumlah Alat } \\
\text { Posbindu Kit }\end{array}$} \\
\cline { 2 - 3 } & SOP & $\begin{array}{c}\text { Hasil } \\
\text { Penelitian }\end{array}$ \\
Pematang Gajah & 1 Paket & 1 Paket \\
Mendalo Indah & 1 Paket & 1 Paket \\
Mendalo Darat & 1 Paket & 1 Paket \\
Simp. Sei Duren & 1 Paket & Tidak Ada \\
Pijoan & 1 Paket & Tidak Ada \\
\hline
\end{tabular}

Tabel 2. Jumlah Kader Posbindu PTM

Jumlah Kader

\begin{tabular}{lccc} 
Desa/Kelurhan & Tipe & \multicolumn{2}{c}{ Aktif } \\
\cline { 3 - 4 } Berposbindu & Posbindu & SOP & $\begin{array}{c}\text { Hasil } \\
\text { Penelitian }\end{array}$ \\
& & & 4 orang \\
Pematang Gajah & Dasar & 5 orang & 2 orang \\
Mendalo Indah & Dasar & 5 orang & 2 \\
Mendalo Darat & Dasar & 5 orang & 5 orang \\
Simp Sei Duren & Dasar & 5 orang & 2 orang \\
Pijoan & Dasar & 5 orang & 4 orang \\
\hline
\end{tabular}

Di Wilayah Kerja Puskesmas Simpang Sungai Duren Tahun 2017 
Evaluasi implementasi berfungsi untuk mengetahui pada tingkatan mana suatu program efektif setelah diterapkan serta memperlihatkan kepada para pengambil keputusan tentang apa yang terjadi dalam program dan bagaimana program telah berkembang $^{14}$. Melalui evaluasi tersebut pada hasil penelitian ini ditemukan beberapa permasalahan pada proses implementasi Posbindu PTM di wilayah Puskesmas Simpang Sungai Duren yakni : 1) pelayanan sistem lima meja belum teratur dikarenakan proses pelaksanaan Posbindu PTM yang bersamaan dengan Posyandu serta belum adanya tempat khusus pelaksanaan Posbindu PTM; 2) rendahnya pengetahuan mengenai Posbindu PTM sehingga sulit mengumpulkan dan mengajak masyarakat untuk mengikuti Posbindu PTM; 3) rendahnya motivasi masyarakat mengikuti kegiatan Posbindu PTM, kunjungan laki-laki dan remaja sedikit dibandingkan kunjungan perempuan,; 4) kurangnya sosialisasi dari kader sehingga masyarakat belum mengenal dan mengetahui pentingnya Posbindu PTM; 5) rendahnya partisipasi masyarakat berperan aktif untuk menjadi kader Posbindu PTM dan; 6) belum semua desa memiliki alat Posbindu Kit tersendiri; 7) kuantitas kader yang belum sesuai SOP.

Jika sarana atau alat tidak sesuai dengan standar maka akan mempengaruhi mutu pelayanan, sarana dan prasarana bagian kebutuhan yang penting dalam memberikan pelayanan untuk mencapai suatu tujuan ${ }^{17}$. Hal ini sangat berpengaruh terhadap keberhasilan implementasi Posbindu PTM, Kader juga sangat mempengaruhi motivasi masyarakat untuk mau mengikuti Posbindu PTM, karena kader yang akan memberikan sosialisasi dan mengenalkan kepada masyarakat mengenai Posbindu PTM serta kurangnya jumlah kader yang akan berperan juga mempengaruhi kemunculan kendala-kendala dalam proses implementasi Posbindu PTM. Sejalan dengan penelitian Maryaningsih (2016) bahwa pemanfaatan Posbindu PTM penting, dibutuhkan peran dan dukungan dari tenaga kesehatan, kader maupun tokoh masyarakat untuk memotivasi timbulnya kesadaran masyarakat untuk memanfaatkan Posbindu $\mathrm{PTM}^{23}$. Perlunya memperluas sasaran komunikasi dan sosialisasi ${ }^{24}$. Perlunya ketersediaan informasi, berupa buku pintar dan brosur serta diperlukannya kelengkapan alat untuk setiap Posbindu PTM ${ }^{25}$.

Kendala pada pelaksanaan Posbindu PTM tersebut membutuhkan perhatian, dukungan dan tindak lanjut seperti: 1) kurangnya pemahaman dan pengetahuan pemangku kepentingan mengenai implementasi Posbindu PTM diperlukan adanya koordinasi dan peningkatan pengetahuan maupun pemahaman dari kader, bidan desa, petugas Puskesmas mengenai Posbindu PTM kepada pemangku kepentingan; 2) kurangnya motivasi dan pemahaman masyarakat mengenai Posbindu PTM membutuhkan peran kader dan petugas puskesmas untuk lebih banyak atau sering melakukan sosialisasi pentingnya Posbindu PTM kepada masyarakat dapat berupa lebih banyak penyebaran informasi melalui media cetak brosur, leaflet poster atau media lainnya. Mengatasi permasalahan tersebut diperlukan pengadaan pelatihan untuk seluruh kader, melakukan kemitraan, dan melaksanakan musyawarah masyarakat desa bersama seluruh pihak baik kader, tokoh masyarakat atau pemangku kepentingan dan petugas puskesmas.

\section{Peran Kader Posbindu PTM}

Berdasarkan hasil penelitian peran kader Posbindu PTM di Wilayah Kerja Puskesmas Simpang Sungai Duren diantaranya pertama, memberikan pelayanan sistem lima meja kepada peserta Posbindu PTM. Kedua, kader 
berperan dalam penyampaian informasi sebelum pelaksanaan Posbindu PTM kepada masyarakat. Ketiga, menyiapkan tempat dan peralatan untuk pelaksanaan kegiatan Posbindu PTM. sedangkan beberapa peran yang belum mampu dijalani yakni melakukan pemantauan berupa pencatatan KMS-FR, pencatatan dan pelaporan hasil kegiatan secara online, memberikan edukasi PTM, melakukan sosialisasi mengenai Posbindu PTM dan memotivasi masyarakat untuk mengikuti kegiatan Posbindu PTM. Hal ini karena tidak semua kader mendapatkan pelatihan kader, buku pedoman teknis pelaksanaan Posbindu PTM dan belum memahami mengenai Penyakit Tidak Menular (PTM) serta peran rangkap kader yang bukan hanya sebagai kader Posbindu PTM dengan pelaksanaan yang bersamaan dengan kegiatan masyarakat lainnya.

Menurut teori Wirawan (2016) menyatakan bahwa perlu adanya evaluasi pengembangan sumber daya manusia dengan tujuan mengukur seberapa besar pengaruh investasi modal (biaya pelatihan, gaji, biaya penyelenggaraan kegiatan). Berdasarkan pedoman penyelenggaraan posbindu PTM yaitu kader Posbindu PTM berperan mengadakakan pertemuan kelompok menentukan jadwal kegiatan, menyiapkan tempat dan peralatan yang diperlukan, membuat dan menyebarkan pengumuman mengenai waktu penyelenggaraan melakukan pelayanan lima meja, memberikan edukasi, konseling, memotivasi dan melakukan pencatatan pelaksanaan kegiatan ${ }^{7}$. Berdasarkan hasil penelitian peran kader di Wilayah Kerja Puskesmas Simpang Sungai Duren belum memenuhi SOP karena masih ada beberapa peran kader yang belum terlaksana.

Penyampaian informasi sebelum pelaksanaan Posbindu PTM dilakukan oleh kader, namun tidak akan sampai dan menyebar secara luas jika informasi tersebut hanya sebatas dari kader, tetapi juga diperlukan peran serta masyarakat dalam mengkomunikasikan informasi tersebut kepada masyarakat lainnya, baik melalui kepala desa atau lurah, tokoh masyarakat, pemuka agama didaerah tersebut, ataupun masyarakat umum. Upaya peningkatan derajat kesehatan ini tidak sepenuhnya diberatkan kepada kader tetapi kader adalah orang yang membantu masyarakat untuk sadar dan mau secara mandiri melakukan upaya-upaya kesehatan melalui kegiatan Posbindu PTM seperti mengikuti aktifitas fisik secara rutin serta memanfaatkan pelayanan sistem lima meja untuk usaha deteksi dini PTM sehingga masyarakat dapat mengetahui dan mencegah kemungkinan PTM terutama pada diri mereka sendiri.

Peningkatan dan pengembangan kompetensi kader dalam menjalankan perannya sangat penting agar proses implementasi Posbindu PTM berjalan optimal. Hal ini dapat dilakukan melalui pengoptimalan pelatihan kader Posbindu PTM dengan mengikut sertakan seluruh kader Posbindu PTM saat pelatihan baik dari segi teknis maupun pengetahuannya oleh petugas Puskesmas sehingga dalam proses megimplementasikan Posbindu PTM kader benar-benar siap dan mampu menjalankan peran sesuai dengan SOP.

Peran kader Posbindu PTM akan berjalan sesuai dengan SOP jika seluruh lapisan masyarakat berpartisipasi dalam menjalankan kegiatan Posbindu PTM ini, tidak hanya menyerahkan kepada kader tetapi juga memberikan dukungan penuh baik dalam hal pengadaan tempat, alat, menambah kuantitas kader, memberikan pelatihan yang berkesinambungan dan buku saku kader maupun menemukan sumber pembiayaan dari semua pihak baik dari masyarakat, forumforum masyarakat, kemitraan swasta, maupun 
dari pemerintah daerah yang memberikan anggaran untuk keberlangsungan peningkatan kompetensi dan peran kader Posbindu PTM.

\section{Peran Petugas Puskesmas pada \\ Pelaksanaan Posbindu PTM \\ Berdasarkan hasil penelitian peran} petugas puskesmas pada pelaksaaan Posbindu PTM di Wilayah Kerja Puskesmas Simpang Sungai Duren diantaranya pertama melakukan penyuluhan atau pemberian informasi kesehatan tentang kesehatan yang berhubungan dengan faktor penyebab Penyakit Tidak Menular (PTM), kedua memberikan bimbingan teknis pelaksanaan kegiatan Posbindu PTM kepada kader seperti bimbingan cara mengukur tekanan darah dan melayani masyarakat yang mengikuti Posbindu PTM, ketiga menerima dan menangani kasus rujukan dari Posbindu PTM, keempat menganalisa hasil kegiatan Posbindu PTM, dan melakukan koordinasi kepada pemangku kepentingan. Ada beberapa peran petugas Puskesmas yang belum terlaksana secara optimal, yakni pemberian bimbingan teknis atau pelatihan hanya dilakukan kepada dua orang kader untuk setiap Posbindu PTM di wilayah tersebut, kurangnya koordinasi dengan pemangku kepentingan mengenai hasil maupun jadwal pelaksanaan Posbindu PTM.

Berdasarkan Kementrian Kesehatan Republik Indonesia tahun 2013 tentang pedoman penyelenggaraan posbindu PTM yaitu petugas puskesmas memiliki peran dalam pelaksanaan Posbindu PTM berupa memberikan bimbingan teknis kepada kader, memberikan materi kesehatan atau penyuluhan PTM, menganalisis hasil kegiatan Posbindu PTM, menerima dan menangani kasus rujukan Posbindu PTM, serta melakukan koordinasi dengan pemangku kepentingan terkait penyelenggaraan Posbindu $\mathrm{PTM}^{7}$. Berdasarkan hasil penelitian peran petugas Puskesmas Simpang Sungai Duren telah memenuhi SOP namun belum optimal.

Beberapa peran yang belum optimal diantaranya, pertama belum melakukan koordinasi secara berkesinambungan dalam kegiatan Posbindu PTM kepada pemangku kepentingan. Kedua belum mampu melatih kader Posbindu PTM secara keseluruhan sesuai SOP karena kurangnya pendanaan untuk pelatihan tersebut sehingga tidak semua kader Posbindu PTM yang memiliki pengetahuan dan pemahaman mengenai Posbindu PTM. Sedangkan Muninjaya dalam Darmawan dan Sjaaf (2016) mengemukakan minimnya ketersediaan dana mempengaruhi moral dan motivasi kerja akan menurun sehingga target program tidak tercapai. Proses implementasi Posbindu PTM tidak akan berjalan dengan baik jika kader-kader Posbindu PTM tidak terlatih. Koordinasi dari petugas Puskesmas kepada pemangku kepentingan sebaiknya tidak hanya sebatas sebelum pelaksanaan atau ketika diawal penentuan jadwal namun koordinasi yang berkelanjutan agar pemangku kepentingan juga bisa memberikan bantuan, melakukan pengawasan terhadap kesehatan masyarakatnya, memberikan arahan ataupun pergerakan lainnya untuk menemukan kebijakan atas permsalahan kesehatan masyarakat khususnya mengenai PTM di wilayah yang berada dibawah tanggung jawab mereka.

Permasalahan pada indikator peran petugas puskesmas dalam implementasi Posbindu PTM berhubungan dengan indikator peran pemangku kepentingan, peran kader dan sumber pembiayaan. Diharapkan dengan adanya evaluasi terhadap indikator peran petugas puskesmas dalam implementasi Posbindu PTM dapat meningkatkan mutu pelayanan atau pengimplementasian Posbindu PTM melalui koordinasi dan komunikasi yang 
baik antara pihak-pihak yang berpengaruh pada implementasi kegiatan tersebut.

6. Peran Pemangku Kepentingan pada Pelaksanaan Posbindu PTM

Pemangku kepentingan pada penelitian ini difokuskan pada kepala desa atau lurah. Peran pemangku kepentingan pada penyelenggaraan Posbindu PTM di Wilayah Kerja Puskesmas Simpang Sungai Duren diantaranya, pertama pemangku kepentingan berperan dalam memotivasi warga untuk mengikuti Posbindu PTM, kedua pemangku kepentingan membantu mengusahakan pengadaan fasilitas untuk pelaksanaan Posbindu PTM. Namun masih ada beberapa pemangku kepentingan yang belum memahami mengenai Posbindu PTM sehingga jarang melakukan koordinasi mengenai Posbindu PTM dan belum bisa membantu penganggaran dana untuk pelaksanaan Posbindu PTM.

Berdasarkan Kementrian Kesehatan Republik Indonesia tahun 2013 tentang pedoman penyelenggaraan posbindu PTM yaitu mengkoordinasikan hasil kegiatan dan tindak lanjut Posbindu PTM di wilayah kerjanya selaku penanggung jawab wilayah serta melakukan pembinaan dalam mendukung kegiatan Posbindu PTM. Berdasarkan penelitian peran pemangku kepentingan pada implementasi Posbindu PTM belum memenuhi SOP.

Berdasarkan teori Mardikanto dan Soebianto (2012) menyatakan untuk mencapai tujuan implementasi kegiatan harus melibatkan semua pihak dan membutuhkan koordinasi yang baik agar semua pihak bergerak serta berpartisipasi didalam implementasi kegiatan tersebut. Teori Patton (2009) menyatakan evaluasi implementasi berfungsi mengetahui seberapa besar program efektif setelah diterapkan serta memperlihatkan kepada para pengambil keputusan tentang apa dan bagaimana program berkembang.

Partisipasi masyarakat dalam pembangunan perlu ditumbuhkan melalui dibukanya forum yang memungkinkan masyarakat banyak berpartisipasi langsung dalam proses pengambilan keputusan tentang program-program pembangunan di wilayah setempat (Mardikanto dan Soebiato, 2012). Partisipasi masyarakat terutama partisipasi pemangku kepentingan dalam menjalankan perannya pada implementasi Posbindu PTM perlu ditumbuhkan dengan membuka forum koordinasi masyarakat untuk menentukan kebijakan atas permasalahan yang ditemukan pada pelaksanaan Posbindu PTM.

Pemberdayaan masyarakat di bidang kesehatan adalah proses pemberian informasi kepada individu, keluarga atau kelompok (klien) secara terus menerus dan berkesinambungan mengikuti perkembangan klien, serta proses membantu klien, agar klien tersebut berubah dari tidak tahu menjadi tahu atau sadar (aspek pengetahuan atau knowledge), dari tahu menjadi mau (aspek sikap atau attitude), dan dari mau menjadi mampu melaksanakan perilaku yang diperkenalkan (aspek tindakan atau practice $)^{26}$. Begitu juga halnya dengan pemberdayaan masyarakat melalui kegiatan Posbindu PTM, kepala desa atau lurah kurang memahami peran mereka selaku penanggungjawab di wilayah kerja mereka dalam pelaksanaan Posbindu PTM, sebaiknya petugas puskesmas dan kader memberikan pemahaman dan pengetahuan lebih lanjut serta lebih sering berkoordinasi mengenai Posbindu PTM kepada kepala desa atau lurah, sehingga mereka tau dan memahami posisi maupun peran mereka dalam proses implementasi Posbindu PTM.

7. Pembiayaan Posbindu PTM 
Pembiayaan untuk penyelenggaraan Posbindu PTM di Wilayah Kerja Puskesmas Simpang Sungai Duren Kecamatan Jambi Luar Kota belum didapatkan secara menyeluruh bahkan ada beberapa desa berposbindu yang tidak memiliki sumber pembiayaan. Berdasarkan hasil penelitian sumber pembiayaan Posbindu PTM berasal dari dana Bantuan Operasional Kesehatan (BOK) dan Anggaran Pendapatan dan Belanja Daerah (APBD), namun pembiayaan tersebut belum mencukupi untuk melatih 5 orang kader Posbindu PTM untuk setiap desa, sedangkan bantuan dari dunia usaha juga belum ada dikarenakan belum adanya kemitraan dengan dunia usaha serta bantuan dana desa juga belum bisa didapatkan karena beberapa desa belum bisa menganggarkan dana untuk pelaksanaan Posbindu PTM.

Minimnya anggaran dana implementasi Posbindu PTM disebabkan oleh, pertama kurangnya pengetahuan cara untuk bermitra dengan dunia usaha atau instansi kesehatan lainnya dan berfikir prosedur untuk bermitra sulit, kedua belum adanya partisipasi masyarakat bersama pemerintah daerah setempat untuk bersama menemukan solusi permasalahan sumber pembiayaan tersebut, dan ketiga beberapa kepala desa atau lurah belum memahami pentingnya pengimplementasian Posbindu PTM serta anggaran dana desa juga minim sehingga dana desa untuk kegiatan Posbindu PTM belum bisa dianggarkan.

Berdasarkan Kementrian Kesehatan Republik Indonesia tahun 2013 tentang pedoman penyelenggaraan posbindu PTM yaitu untuk mendukung pelaksanaan Posbindu PTM membutuhkan pembiayaan yang memadai, baik dana mandiri, kelompok masyarakat, kemitraan melalui program CSR (Corporate Social Responsibility) serta bantuan donatur yang peduli terhadap permasalahan PTM. Berdasarkan penelitian
Pembiayaan untuk penyelenggaraan Posbindu PTM di Wilayah Kerja Puskesmas Simpang Sungai Duren belum memenuhi SOP.

Kurangnya sumber dana tersebut sangat berpengaruh terhadap proses implementasi Posbindu PTM seperti kinerja kader menjadi kurang optimal dalam memberikan pelayanan Posbindu PTM dan kurangnya motivasi masyarakat untuk mengikuti Posbindu PTM dikarenakan mereka harus membayar untuk pemeriksaan tersebut, sehingga perlunya peningkatan koordinasi dan kemampuan dalam menjalin kemitraan agar sumber dana mampu memenuhi kebutuhan proses implementasi Posbindu PTM.

8. Pencatatan dan Pelaporan Pelaksanaan Posbindu PTM

Berdasarkan hasil penelitian Pencatatan pelaksanaan Posbindu PTM di Wilayah Kerja Puskesmas Simpang Sungai Duren dilakukan oleh kader dan bidan desa Posbindu PTM secara manual dalam format pencatatan offline dikarenakan kader belum diberikan pelatihan penginputan hasil pelaksanaan Posbindu PTM secara online. Pencatatan pada Kartu Menuju Sehat Faktor Risiko Penyakit Tidak Menular (KMS-FR PTM) dilakukan oleh bidan desa dikarenakan kader belum memahami mengenai edukasi kesehatan PTM.

Tujuan evaluasi program diantaranya untuk mendapatkan informasi mengenai perencanaan dan pelaksanaan suatu program, memperbaiki kebijakan perencanaan dan pelaksanaan program yang akan memberikan informasi mengenai hambatan dalam pelaksanaan program, dan untuk memperbaiki alokasi sumber daya manajemen ${ }^{17}$. Kendala dalam melakukan pencatatan yakni sulitnya mendapatkan identitas dan data-data dari masyarakat karena merasa merasa malas dan tidak mengetahui fungsi pendataan tersebut. Kader membutuhkankan peningkatan pengetahuan dan pemahaman mengenai pencatatan dan edukasi pada penggunaan 
KMS FR PTM, sehingga bukan bidan desa lagi yang melakukan pencatatan dan edukasi mengenai KMS tersebut.

Berdasarkan Kementrian Kesehatan Republik Indonesia tahun 2013 tentang pedoman penyelenggaraan posbindu PTM yaitu pencatatan hasil kegiatan Posbindu PTM dilakukan oleh kader, petugas puskesmas mengambil data hasil kegiatan yang digunakan untuk pembinaan dan melaporkan ke instansi terkait secara berjenjang. Berdasarkan hasil penelitian Pencatatan dan pelaporan pelaksanaan Posbindu PTM di Wilayah Kerja Puskesmas Simpang Sungai Duren memenuhi SOP, namun belum terlaksana secara optimal.

Pencatatan dan pelaporan sangat diperlukan untuk melihat dan mendeteksi masyarakat yang sehat, berisiko atau akan berisiko pada PTM, sehingga dibutuhkan ketepatan dan pembaharuan data yang akurat dari kader maupun petugas kesehatan secara berkala, kader maupun petugas kesehatan juga lebih aktif memberikan penjelasan atau sosialisasi pentingnya mengikuti Posbindu PTM dan memeberikan data diri secara tepat dan akurat sehingga akan memotivasi masyarakat untuk mau memberikan informasi mengenai data diri dan riwayat penyakit kepada kader, kemudian kader bisa memberikan data yang tepat dan akurat.

\section{KESIMPULAN DAN SARAN}

Berdasarkan penelitian yang dilakukan mengenai evaluasi proses implementasi Pos Pembinaan Terpadu Penyakit Tidak Menular (Posbindu PTM) di wilayah kerja Puskesmas Simpang Sungai Duren didapatkan kesimpulan sebagai berikut :

1. Tahapan proses implementasi Posbindu PTM di Wilayah Kerja Puskesmas Simpang Sungai Duren Kecamatan Jambi Luar Kota Kabupaten Muaro Jambi diantaranya waktu penyelenggaraan rutin minimal satu kali dalam satu bulan, tempat pelaksanaan Posbindu PTM tidak menetap di satu tempat khusus atau dilaksanakan berpindah-pindah tempat, kader berperan memberikan pelayanan sistem lima meja dan penyempaian informasi pelaksanaan Posbindu PTM, peran petugas puskesmas melakukan penyuluhan atau pemberian informasi kesehatan kepada masyarakat dan melakukan bimbingan teknis atau pelatihan kader, peran pemangku kepentingan memberikan motivasi dan membantu pengadaan fasilitas, pembiayaan belum didapatkan secara menyeluruh serta pencatatan dan pelaporan dilakukan oleh kader Posbindu PTM masih secara manual.

2. Proses implementasi Posbindu PTM di Wilayah Kerja Puskesmas Simpang Sungai Duren Kecamatan Jambi Luar Kota Kabupaten Muaro Jambi yang telah memenuhi Standar Operasional Prosedur (SOP) diantaranya waktu pelaksanaan, pelaksanaan kegiatan, peran petugas puskesmas, serta pencatatan dan pelporan. Sedangkan yang belum memenuhi SOP diantaranya tempat pelaksanaan, peran kader, peran pemangku kepentingan dan pembiyaan Posbindu PTM.

Berdasarkan kesimpulan hasil penelitian, maka saran yang dapat diberikan yaitu :

1. Bagi Dinas Kesehatan Kabupaten Muaro Jambi

Memberikan pelatihan kepada pengelola program Posbindu PTM di Puskesmas dalam peningkatan kemampuan untuk menjalin kemitraan. Bekerjasama dengan Dinas Kesehatan Provinsi Jambi dalam memperbanyak pengadaan dan 
penyebaran media informasi Posbindu PTM disetiap Posbindu PTM.

2. Bagi Puskesmas Simpang Sungai Duren

Meningkatkan kemitraan membantu dukungan pendanaan maupun alat pelaksanaan posbindu PTM. Menambah jumlah kader Posbindu PTM yang disesuaikan dengan SOP. Memberikan pelatihan kepada seluruh kader Posbindu PTM. Meningkatkan koordinasi dan memberikan laporan tidak hanya lisan tapi juga tulisan. Melakukan musyawarah masyarakat desa

3. Bagi Institusi Pendidikan

Melakukan kerjasama anatara institusi pendidikan dengan Puskesmas yang membentuk Posbindu PTM untuk membantu mengoptimalkan implementasi Posbindu PTM serta sebagai upaya peningkatan kemampuan, pengetahuan, dan pemahaman mahasiswa mengenai Posbindu PTM melalui kegiatan praktek mata kuliah atau pengabdian masyarakat yang mengikutsertakan mahasiswa pada kegiatan tersebut.

4. Peneliti Selanjutnya

Melakukan penelitian mendalam mengenai evaluasi proses pelaksanaan Posbindu PTM tidak hanya kepada pelaksana tapi juga kepada sasaran Posbindu PTM agar mengetahui lebih mendalam penyebab kendala-kendala yang ditemukan pada proses implementasi Posbindu PTM

\section{DAFTAR PUSTAKA}

1. Bustan NM,. 2015. Manajemen Pengendalian Penyakit Tidak Menular. Jakarta: Rineka Cipta.

2. Kemenkes RI., 2012. Buletin jendela data dan informasi kesehatan. (48 layar). Diunduh dari URL: https://www.depkes.go.id/pusdatin/bul etin/ptm.pdf (diakses 6 Sept 2017)

3. Kemenkes RI., 2013. Riset kesehatan dasar tahun 2013. (306 layar). Diunduh dari URL:http://www.depkes.go.id/resource s/download/general/Hasil\%20Riskesda s\%202013.pdf (diakses 7 Agst 2017).

4. Menkes RI., 2017. Peraturan menteri kesehatan Republik Indonesia nomor 5 tahun 2017 tentang rencana aksi nasional penanggulangan penyakit tidak menular tahun 2015-2019. (67layar).DiunduhdariURL:http://dink es.babelprov.go.id/sites/default/files/do kumen/produk_hukum/PMKNo.5ttgRe ncanaAksiNasionalPenanggulanganPT $\underline{\text { M20152019_.pdf }}$ (diakses 22 Sept 2017).

5. Kemenkes RI. 2014. Profil kesehatan Indonesia tahun 2013. (391 layar). DiunduhdariURL:http://www.depkes.g o.id/resources/download/pusdatin/profi 1-kesehatan-indonesia/profil-

kesehatan-indonesia-2013.pdf (diakses 15 Sept 2017).

6. Dinas Kesehatan Provinsi Jambi. 2015. Profil kesehatan provinsi jambi 2014. Diunduh dari URL:http://www.depkes.go.id/resource s/download/profil/PROFIL_KES_PRO VINSI_2014/05 Jambi_2014.pdf (diakses 6 Sept 2017)

7. Kemenkes RI., 2013. Buku pintar kader penyelenggaraan posbindu ptm. Seri ke-1. Jakarta: Kemenkes RI. 
8. Kemenkes RI. 2017. Data dan informasi profil kesehatan Indonesia 2016;

layar).DiunduhdariURL:http://www.de pkes.go.id/resources/download/pusdati n/lainlain/DatadanInformasiKesehatan Profil KesehatanIndonesia2016smallersize-web.pdf (diakses 6 Sept 2017)

9. Parinduri, SK., 2015. Analisis pelaksanaan program pos pembinaan terpadu penyakit tidak menular (posbindu ptm) dalam deteksi dini dan pencegahan komplikasi diabetes melitus di puskesmas glugur darat tahun 2014. (119 layar). Diunduh dari URL:

http://repository.usu.ac.id/handle/1234 56789/54082 (diakses 6 Sept 2017)

10. Indah, DT., 2015. Evaluasi input sistem survailans hipertensi di wilayah kerja dinas kesehatan kota magelang berdasarkan pedoman sistem surveilans penyakit tidak menular. Skripsi Sarjana. Jurusan Ilmu Kesehatan Masyarakat. Universitas Negeri Semarang, Jawa Tengah. (170 layar). Diunduh dari URL: http://lib.unnes.ac.id/20395/1/6411410 102-S.pdf (diakses 6 Sept 2017).

11. Astuti, ED., Prasetyowati, I., \& Ariyanto, Y., 2016. Gambaran proses kegiatan pos pembinaan terpadu penyakit tidak menular di puskesmas sempu kebupaten banyuwangi. 4 (1), p.2,

DiunduhdariURL:https://jurnal.unej.ac. id/index.php/JPK/article/view/2594/20 $\underline{81}$ (diakses 6 Sept 2017)

12. Satori, D., \& Komariah, A., 2014. Metodologi penelitian kualitatif. Bandung: Alfabeta.

13. Creswell, JW. 2015. Research design, pendekatan kualitatif, kuantitatif dan mixed. Edisi ke-tiga. Yogyakarta: Pustaka Belajar.

14. Patton, MQ. 2009. Metode evaluasi kualitatif. Yogyakarta : Pustaka Belajar.

15. Moleong, LJ., 2017. Metodologi penelitian kualitatif edisi revisi. Bandung: PT Remaja Rosdakarya.

16. Ibrahim., 2015. Metodologi penelitian kualitatif, panduan penelitian beserta contoh proposal kualitatif. Bandung : Alfabeta.

17. Darmawan, AS., \& Sjaaf, CA., 2016. Administrasi Kesehatan Masyarakat. Jakarta: Rajawali Pers.

18. Febrianti, S. 2017. Komunikasi partisipatif pada program pos pembinaan terpadu. 5(2) 2017: 110 123ISSN 2502-5961. Diunduh dari URL : http://ejournal.ilkom.fisipunmul.ac.id/site/wpcontent/uploads/2017/06/JURNAL\%2 0(06-06-17-06-33-15).pdf (diakses 3 Okt 2017)

19. Laelawati E. 2017. Panduan musyawarah masyarakat desa (MMD). Diunduh dari URL https://edoc.site/queue/2-panduanmmd-pdf-free.html (diakses 8 Februari 2018)

20. Mardikanto, T., \& Soebiato, P., 2012. Pemberdayaan masyarakat dalam perspektif kebijakan publik. Bandung: Alfabeta.

21. Azwar, A., 2015. Pengantar administrasi kesehatan. Edisi ke-tiga. Jakarta: Binarupa Aksara.

22. Wirawan. 2016. Evaluasi, teori, model, metodologi, standar, aplikasi dan profesi. Jakarta: Rajawali Pers.

23. Maryaningsih. 2016. Hubungan persepsi dengan pemanfaatan pos pembinaan terpadu di wilayah kerja puskesmas helvetia medan. Vo 1 , no 1 , 
ISSN 2548-3943. Diunduh dari URL : http://stikes-sitihajar.ac.id/wpcontent/uploads/2018/03/06_Maryanin gsih.pdf. (diakses 22 Sept 2017).

24. Jayusman, TAI \& Widiyarta, A. 2016. Efektivitas program pos pembinaan terpatu (posbindu) penyakit tidak menular (ptm) di desa anggaswangi kecamatan sukodono sidoarjo. Diunduh dari URL : http://eprints.upnjatim.ac.id/7316/1/ag us_widiyarta.pdf. (diakses 3 Okt 2017)

25. Febrianti, R., \& Prabawati, I. 2016. Implementasi pelaksanaan pos pembinaan terpadu penyakit tidak menular (posbindu ptm) di puskesmas pucang sewu kota Surabaya. Diunduh dariURL:https://jurnalmahasiswa.unes a.ac.id/index.php/publika/article/viewF ile/21022/19285 (diakses 6 Sept 2017)

26. Kemenkes RI. 2013. Peraturan menteri kesehatan republik Indonesia tentang pedoman pelaksanaan dan pembinaan pemberdayaan masyarakat bidang kesehatan. Diunduh dari URL:https://peraturan.bkpm.go.id/jdih/ userfiles/batang/PMK\%20No.\%2065\% 20ttg\%20Pemberdayaan\%20Masyarak at\%20Bidang\%20Kesehatan.pdf. (diakses 8 Februari 2018) 